\title{
In this Issue of KRITIKE: An Online Journal of Philosophy
}

Paolo A. Bolaños

$\mathrm{T}$ he Editorial Board of KRITIKE: An Online Journal of Philosophy is happy to release the journal's eighth edition, marking the culmination of the year 2010. The essays in this edition tackle, in varying degrees but all of sterling quality, issues on language and hermeneutics, society and the problem of commodification, mediated psychopathy, education, postcolonial discourse, political resistance, the reception of critical theory, and also on more philological treatments of the works of Plato, Nietzsche, and Kant. The interdisciplinary character of these essays and the cross-pollination of theoretico-critical discourses demonstrated by them are not to be missed.

The so called "linguistic turn" in Western philosophy has an indefinitely long and complex history. The phrase was itself coined by the Austrian philosopher and member of the Vienna Circle, Gustav Bergmann, during the early $20^{\text {th }}$ Century, to refer to the philosophical study of language, understood by Analytic philosophers as propositional logic. This philosophical preoccupation with language, however, cuts through the Continental-Analytic divide. As a matter of fact, Plato already mentioned the significance of speech in philosophy in the Timaeus and also took issue with the normative character of names in the Cratylus. A similar concern about language reemerges during the $18^{\text {th }}$ Century via the works of Johann Georg-Hamann, who analyzed the constitutive function of language in thought. This is followed through by the Hermeneutical tradition, championed by Friedrich Daniel Schleiermacher. The philosophical study of language is carried over by more contemporary hermeneutical philosophers, especially Paul Ricoeur. The hermeneutics of symbols is the theme of the first essay, under the Articles section, written by Alexis Deodato S. Itao. At the outset of his paper, Itao attempts to recast Ricoeur as a "critical theorist" who is committed to a notion of "social transformation" and "progressive politics." This, Itao does, not to undermine Ricoeur as a hermeneutical philosopher, but to argue that Ricoeur's "critical theory" is grounded in his hermeneutics. In other words, with a hermeneutical philosophy based on the dialectical and constitutive role of language (expressions) in the formation of the subject, Ricouer, Itao maintains, is able to reinforce the critical stance of his project—one which veers away from a naïve conception of consciousness as immediate. Consciousness is never immediate because it is necessarily conditioned by language. Itao argues that this critical (suspicious) outlook on consciousness and language, far from a complete

(C) 2010 Paolo A. Bolaños

http://www.kritike.org/journal/issue 8/editorial december2010.pdf ISSN 1908-7330 


\section{ii IN THIS ISSUE OF KRITIKE}

denial, salvages the "symbolic" character of our conceptual "idols" (e.g., Cartesian Cogito); these symbolic images are the bases of any reflection, our "faith" in them allows us to recover meaning. Finally, Itao argues that Ricoeur's hermeneutic suspicion over symbols could instigate reflection over the flighty contrast between "political passion" and "political vocation." Meanwhile, Angelo Bottone's "The Vanishing Mediator and Linguistic Hospitality" begins with an important insight from Ricoeur: translation is "a paradigm of the attitude towards the other." This means that the ethical purpose of language becomes the normative basis for any kind of hospitality. Bottone's aim, however, is to contrast Ricoeur's statement to that of the French political philosopher Etienne Balibar, who thinks that Europe should act as the "interpreter of the world." According to Bottone, the affinity between Ricoeur and Balibar is undeniable, but, nevertheless, there are important differences. The essay shows that language, more specifically the dynamics of languages in Europe, is at the centerpiece for both Ricoeur and Balibar. For Balibar, the main concern is about the construction of a form of democracy which could accommodate the various languages in Europe, which translate into the myriad of cultural backgrounds, ethnicities, and political positions. For his part, Ricoeur is concerned about the possible "mediation" of a polymorphous Europe. It is clear from Bottone's discussion that both Balibar and Ricoeur are proposing a kind of "global" citizenship, wherein inclusivity, rather than exclusivity, is the normative ground. This inclusive gesture is only possible through a non-opprobrious ethico-political gesture that conditions the possibility of socio-political change, such as, the "vanishing mediator" (Balibar) or "linguistic hospitality" (Ricoeur). Nonetheless, the basic difference, according to Bottone, is that Balibar's vanishing mediator argument tends towards a kind of nihilism of identity, crippling the very possibility of ethnic-to-ethnic dialogue; while Ricoeur acknowledges the ontological status, and, hence, the socio-political importance of dialogical interpretation wherein the very ethnicity of the interpreter becomes a starting point of true dialogue. In the third essay, Daniel Hourigan focuses on the American novelist Chuck Palahniuk's novel Diary; more specifically, on how the "violence of language" is illustrated in the novel; what is key, however, is how Hourigan shows the reflexivity of the style of Palahniuk, as the novel is presented as "a type of auto-critique of Palahniuk's own systemic violence against traditional narrativisation that creates a unique system of relations between the reader and the story." Hourigan notes that Palahniuk's narrative style, "minimalist aesthetic," resembles the Romantic tendency of accepting chaotic nature, the very substratum of civilization or our mundane everyday life. According to Hourigan, the critical performance of Palahniuk's narrative is gleaned from his deviation from traditional narrative techniques to the use of experimental gestures, such as, repetition of key themes and intentional misspelling. Towards the end, Hourigan observes that the Diary is Palahniuk's attempt to transgress a social code via a critical "misuse" of language.

The essays "The Mystical Force of Money" by Edward Erikson and "Commodity, Sign, and Spectacle: Retracing Baudrillard's Hyperreality" by 


\section{P. BOLAÑOS iii}

Daryl Y. Mendoza share a common trajectory: the critique of the commodification of society initiated by Karl Marx. For his part, Erikson analyses the nature of money via a rereading of Marx's Economic and Philosophical Manuscripts of 1844 and Capital. To be more precise, Erikson veers away from the usual reading of these Marxists texts as Marx's "scientific" studies of the money-form and, instead, presents a somewhat sophisticated hermeneutic that blurs the line between literary and scientific. Out of this rereading, Erikson wants to "un-cover the transformative force and violence implicit in the concept of money as the universal exchange form." Erikson's method is worth noting: a teasing out of the figurative language and literary tropes and their tensional relation to the scientific and descriptive language in Marx's works. Aside from the tensional relation between the figurative and descriptive in the works of Marx, Erikson also shows how language itself functions to animate commodities, that is to say, inert commodities are given a human face through language. Mendoza, meanwhile, offers us a comprehensive reconstruction, in spite of the author's caveat that his exposition is not in-depth, of Jean Baudrillard's notion of "hyperreality." In the process of reconstructing the notion of hyperreality, Mendoza focuses on the semio-linguistic study of commodity, a move beyond the Marxist analytic. Mendoza seems to be arguing that Marx failed to analyze the linguistic basis of commodity fetishism. Moreover, Menodza shows that from a semio-linguist reading of the problem of commodity, more precisely, the prognosis of the proliferation of "sign" in society or the "complexification of the abstraction of the exchange form" or the construction of "social consciousness bombarded with images, amplified by Mass Media," a relationship of "spectacle" is set in place, wherein sociopolitical relationships are reduced to "appearances" or "brand names and labels" - "subjects to objects, and subjects to other subjects." Ultimately, what the essay of Erikson and Mendoza rehearse is the critical point also emphatically forwarded by neo-Marxists like George Lukács and Theodor Adorno: the continuous reification of society, where concrete objects are replaced by phantom labels.

Roland Paulsen's "Mediated Psychopathy-A Critical Discourse Analysis of Newspaper Representations of Aggression" is a thorough analysis of the phenomenon of "psychopathy" from several standpoints: sociology, psychology, and philosophy. In order to narrate the story of the possible "ideological" content in the prevailing discourse on psychopathy, the author reconstructs the popular notion of psychopathy based on several accounts in newspapers. From this, the paper seems to be arguing that there is a tendency for the prevailing discourse to take the invariable nature of psychopaths as a given, thereby resulting in a "reified" image of aggression warranted by the language of biology and psychiatry. Paulsen makes a very good job in reconstructing the biological-psychiatric account of psychopathy and his use, albeit selective, of critical insights primarily from the Frankfurt School tradition is well-founded.

The essay of Rhoderick John S. Abellanosa seeks to develop a reflexive-analysis of Richard Rorty's philosophy of education via an exposition 


\section{iv IN THIS ISSUE OF KRITIKE}

of the latter's "Hermeneutics, General Studies, and Teaching." As a matter of fact, Abellanosa's paper attempts more than just an exposition of Rorty's philosophy of education. Quite implicitly, there is also the attempt to introduce some basic themes in Rorty's oeuvre, such as, the nature of truth and knowledge, the reception of the Pragmatic tradition, and Rorty's relation to the hermeneutics of Hans-Georg Gadamer. Abellanosa's discussion of these basic themes in Rorty paints what he deems as Rorty's philosophy of education. The overall thrust of the paper is the effort to contextualize Rorty's view of education to counter the specious view that Rorty succumbs to vulgar relativism because of his relentless critique of the established articles of faith of traditional education. Rorty's, Abellanosa notes, is an earnest attempt to subvert dogmatism by exposing the intricate relationship between the humanities and the sciences. At the end of the paper, it is argued that Rorty advocates a form of education oriented in the community, "a process which every individual must be involved in and take responsibility."

"Kant's Reflections on the Unity of Consciousness, TimeConsciousness, and the Unconscious" by Ben Mijuskovic addresses "the question concerning the ultimate premise of the Transcendental Analytic in Kant's Critique of Pure Reason." Mijuskovic attempts to shed light on Kant's notion of consciousness via Lebnizian lenses, highlighting consciousness' dynamic quality, continuity, and unconscious aspects. The underlying theme of the paper is the phenomenon of human "loneliness," and Mijuskovic speaks of loneliness within the context of the temporality of human consciousness and its psychological effects. According to Mijuskovic, "the epistemological status of temporal consciousness is inextricably intertwined with human consciousness," which implies that the human soul is solitary, insular, and monadic, that is to say, the utter loneliness of man.

Meanwhile, Kristian Urstad declares that, although there is no explicit mention of the name of Callicles, one of Plato's characters in the Gorgias, in Friedrich Nietzsche's corpus, there is strong evidence that some of the latter's famous doctrines were inspired by imageries set forth by the character of Callicles in the dialogue. Urstad, then, presents a comparison between Nietzsche and Callicles, specifically, on their similar views on "happiness and its various components or relations," such as, pleasure and courage. Urstad notes that both Callicles and Nietzsche regard happiness or the good life to be "marked by a significant amount of pain, discomfort, and labor." They, however, differ in their conceptions of power. Nietzsche, for Urstad, offers a more comprehensive account of power.

In "Narratives and the Dialogue of Cultures of Knowledge: A Perspective on the Experience of the West and Africa," Uchenna Okeja recounts the tendency towards "dialogue" between cultures of knowledge in various academic fields, posing a kind of progress in academic fields. This tendency, according to Okeja, also involves a challenge: "This challenge is that of narratives of the various cultures of knowledge that have given birth to ossified discursive historicity that effectively operate behind the scenes of the dialogue." The essay is, therefore, a problematization of the normative 


\section{P. BOLAÑOS}

foundation of narrative (that is, telling a story about a group people) and dialogue (the attempt to bridge essentially different worldviews). Okeja seems to be arguing that the Western bias against black people lurks behind any attempt to describe the African people and their culture, as well as any attempt at a dialogical encounter; the latter is haunted by the subtle language of racism. Okeja concludes that the Western story about Africa-via the narratives of anthropology, literary people like Conrad, and philosophers like Kant-is a "testimonial" or "hermeneutical" injustice. Because each instance fail to listen to Africa and the African people.

The last essay under the Articles section by Cetin Balanuye seeks to present a Deleuzian critique of two contrasting forms of political resistance in Turkey (particularly the widespread Islamization of Turkish society), between the composer Fazil Say and the daburka player Misirli Ahmet. As artists, the reactions of Say and Ahmet could be deemed as aesthetic; nonetheless, Balanuye argues that there is a stark difference between Say- and Ahmet's aesthetic resistance to the degradation of political life in Turkey. According to Balanuye, while Say expresses his political misgivings through "expressionopinion," Ahmet expresses his through "expression-becoming." Following Deleuze, Balanuye argues that the political force of expression-becoming is more powerful compared to expression-opinion because the former is seen as the materialization of resistance via the artwork (where the artist becomes the artwork itself, thus, the very embodiment of resistance) while the latter could be deemed as an "escapist" gesture.

The last piece in this issue, under the Denkbild section, is the third installment of F.P.A. Demeterio's sixth-part Philosophical Fiction on "Critical Theory in the Philippines." Demeterio's "Elixirs and Fabulous Potions" is a continuation of the life-story of Peter Mariano, presented as a sub-story about the blatant commercialization of education in the Philippines. This sub-story focuses on the struggle of Faith Contreras-Fernandez, an Instructor of Industrial Chemistry, with the established status quo-a struggle Faith shares with many Filipino scientists-lack of funding from the government, the obliviousness of the present order to true scientific progress.

To close this Editorial, I would like to express my gratitude to the following individuals who graciously helped out in the completion of this eight edition: my colleagues from the UST Department of Philosophy, Jonathan Villacorta, Tracy Ann Llanera, and Carlos Luz; Dr. Oscar Bulaong and Dr. Mark Calano of Ateneo de Manila University; Renato Manaloto of the University of the Philippines-Diliman; and Dr. Robert Sinnerbrink of Macquarie University, Australia. My gratitude also goes to Marella Ada Mancenido-Bolaños for her gentle reminders.

Finally, on behalf of the KRITIKE Editorial Board, I wish to acknowledge the generosity of the UST Department of Philosophy, headed by Prof. Dr. Alfredo P. Co, for granting subsidy for the publication of future issues of the journal. 